\title{
Feasibility Research on Introduction of Outward Bound by University Physical Education Curriculum in Shandong, China
}

\author{
Qingshan $\operatorname{Sun}^{1}$ \\ ${ }^{1}$ Department of Physical Education, Qingdao University of Science and Technology, Qingdao, China \\ Correspondence: Qingshan Sun, Department of Physical Education, Qingdao University of Science and \\ Technology, Qingdao 260042, China. E-mail: sunqs099@163.com
}

Received: May 17, 2013 Accepted: May 31, 2013 Online Published: June 28, 2013

doi:10.5539/ass.v9n9p80 URL: http://dx.doi.org/10.5539/ass.v9n9p80

\begin{abstract}
Outward bound is a brand-new learning method and training mode of modern people and modern organizations. Organic combination of physical education class with outward bound is one of the directions and tendencies of physical education reform in the future. How to introduce this feasible and effective quality-oriented cultivation method into university physical education curriculum system and implement quality-oriented education has become a pioneering subject with great significance. This paper studies whether it is necessary to introduce outward bound into university physical education curriculum in Shandong Province by means of studying the necessity and feasibility of introducing outward bound in university physical education class and analyzing the implementation result at present.
\end{abstract}

Keywords: physical education curriculum, introduction, outward bound, feasibility

\section{Introduction}

In the modern society where competition becomes fierce and changes take place rapidly, the demand on the comprehensive competence of talents becomes higher. Innovation capacity, adventure attitude, personality, quality, good faith, working attitude, and the confidence and philosophy of risk-taking and facing up to challenges are the most important elements for success of talents in the future. Outward bound is also termed as extended training and is a kind of experiential learning mode of "learning by doing". It is a curriculum designed for the characteristics of the research objects by referring to the achievements of the disciplines of organizational behavior, psychology, pedagogy and management. Outward bound is a kind of experiential training method which requires firsthand experience and joint participation and which makes use of some typical activity scenarios to enable the participants to play their own potential, overcome their psychological disorder, set their wits to work and complete the team work with the power of the team. School physical education is an important component of quality-oriented education. Implementation of outward bound in universities enables students to continuously challenge themselves, hone their will and perseverance, cultivate their up-and-coming life attitude and healthy psychological quality and strengthen their team cooperative consciousness in the process of responding to challenges and resolving problems. Thus, implementation of outward bound is of great realistic significance to both the physical and mental development of students. Shandong belongs to an eastern economically developed region where although social outward bound has been carried out for a short period of time, the development speed is fast and its social influences are obvious. People have accepted and favored such movement and have come to realize its value. Some universities in other provinces have also constructed the field for outward bound, while universities in Shandong Province have not yet opened outward bound courses, which is a great pity. Implementation of outward bound courses in university physical education in Shandong Province has referable, complete and normative cases both in terms of theoretical system and in terms of successful organizational experiences. Knowledge and interest of students is a good basis for universities to open outward bound courses. Field and apparatus also provide convenient conditions for universities to open outward bound courses. Therefore, it is quite necessary and important for universities to speed up opening outward bound courses. This can not only enable students to experience the practice value and effect they are unable to experience in the traditional physical education class, but is also a great improvement of previous physical education courses and a new highlight in the physical education reform in universities. 


\section{Brief Introduction to Outward Bound}

Outward bound originates from the western word outward-bound, which means a small boat leaves a safe harbor and heads for proud sea to rise to the occasion. During the Second World War, quite a large number of vessels on the Atlantic Ocean sank as a result of attack from the hostile forces. Consequently, a lot of sailors fell into water, and a large majority of them unfortunately sacrificed as the seawater was ice-cold and the sea was far away from the land. However, there were still a tiny minority of sailors returned alive after undergoing torment for a long time. Afterwards, it was found that those who returned alive were not the ones who were physically strong, but, instead, were those who had a strong desire to survive. Then, the philosophy was put forward that "success does not depend on abundant physical agility, but powerful willpower." After the Second World War, the unique originality and training mode of outward bound was gradually promoted from the United Kingdom. In 1971, Pich from UK brought "outward bound" into school education. In the 60 s and 70 s in the $20^{\text {th }}$ Century, quality development was spread to Hong Kong and was translated as "outward bound". In 1995, quality development was brought into China and the first quality development school was established in Beijing. In 2002, quality development bases were established in Mao'er Mountain in the Northeast China, Shennongjia in Hubei and Daming Mountain in Zhejiang. Afterwards, quality development was rapidly promoted all over the country and the training objects were extended from sailors to soldiers, students and industrial and commercial employees, and the training target was also extended from purely physical agility and survival skill training to psychological training, personality training and management training.

Outward bound is a kind of experiential learning method, which requires a team and individuals to experience a series of tests, hone their willpower to overcome difficulties, cultivate their healthy psychological quality and up-and-coming life attitude and strengthen their cooperative team consciousness by means of specially designing pertinent and challenging courses and making use of all kinds of typical scenes and activities. Outward bound is not simply a kind of game, but, instead, an experiential inspiration and shocking philosophy. It is a comprehensive refinement and synthesized supplement of the traditional education and is a part of physical education. Its programs are quite close to life and are of great significance to the realistic life of students. Its most characteristics is experience and perception, namely, to enable students to perceive philosophy of life in the process of experience.

\section{An Analysis of the Necessity of Introducing Outward Bound to Universities in Shandong Province}

\subsection{Outward Bound Is an Effective Approach to Carry out Quality-oriented Education}

The great distinction between outward bound and traditional physical education is that the former is centered by students and based on "learning" of students. Outward bound enables students to have a feeling that they are the master of learning and the subject of the teaching process and are able to experience personally that learning is an utmost joy in the process of full participation. In outward bound, teachers have the opportunity to become a member to face together difficulties and share common experiences with students. This helps to establish a nice relationship between teachers and students and change the traditional rigid teaching mode in which students are merely responsible for teaching and students merely for learning. Therefore, outward bound has a positive effect on implementation of quality-oriented education and cultivation of inter-disciplinary talents with its flexible and versatile teaching content.

\subsection{Outward Bound Focuses on Team Cooperation Spirit}

Outward bound practices group activity, emphasizes collective cooperation and attempts to make each student exert all his energy to gain reputation for the collective group, and, meanwhile, to absorb powerful strength and confidence from the collective group and highlight their personality in the collective group. Most of university students nowadays are the only child, so they have strong sense of individualism and weak capacity in team cooperation, unable to be independent. All these are the greatest vulnerabilities of these students after they step towards a social working position. However, outward bound is exactly able to change these vulnerabilities of students. It enables students to resolve problems in the collective cooperation and in contradictions, enhance their capacity of adapting to the society, experience the philosophy of life, cultivate their collectivism spirit through personal experience and manifest their personal characteristics. The fantastic feature of outward bound is that it integrates this profound educational connotation into quite a lot of vivid and dramatic trainings and let the vast majority of participants unconsciously undergo the severe test of the team spirit. For instance, "getting through the power grid", "making a raft", and "survival at sea" are all typical games which emphasize cultivation of the teamwork spirit. Although these games are small, the life philosophy they imply are extremely profound and participants come to profound realization that victory is impossible without planning and success is impossible without cooperation. 


\subsection{Outward Bound Focuses on Healthy Psychological Quality}

Outward bound is able to foster a good psychological quality of students and improve their emotional quotient index, especially their willpower quality. The degree of difficulty in outward bound determines the degree of the willpower required on the part of participants. Training that has certain degree of difficulty but requires the participants to make efforts to succeed has the particular efficacy of cultivating students' willpower quality, strengthen the self-dignity and self-confidence of training subjects, and facilitate the training subjects to possess a capacity of correctly evaluating themselves, which is helpful to form a self-concept. What the outward bound emphasizes is "it's not that you can't, but you dare not to; it's not a problem of your capacity, but a problem of your psychology; and a positive attitude is a motive power for you to gain success." In the particular environment of outward bound, one has to face all kinds of difficulties and challenge extreme psychological fear. It is the key to success whether one is able to adjust the mind in due time, take control over his emotion and take one step forward decisively and bravely. Outward bound makes one come to realize that he has possessed a decisive, confident and bold psychological quality and any difficulty and crisis will be readily solved. It is just like a safe psychological experimental field full of sincerity and challenges. It requires the students to continuously overcome their psychological fear, enhance the capacity of emotional adjustment and self-regulation, keep a gentle mind, have the courage to challenge themselves and defeat themselves and cultivate a calm, decisive and hard-bitten attitude. Therefore, participation in an outward bound has a positive promotion effect on the psychological health of students.

\subsection{Outward Bound Focuses on Excavating People's Potentials and Creativity}

The programs and patterns of the outward bound form particular and even austere test on the mind, intelligence and physical strength of people. In the contemporary society, innovation is the soul of knowledge economy and creativity is an important standard to measure the quality of scientific talents. Cultivation of students' creativity and innovative spirit is the priority of quality-oriented education. It is the priority among priorities in outward bound to stimulate students' imagination potential and cultivate students' creativity. A lot of programs in outward bound are designed for cultivating students' innovative spirit. For example, "can shoes", "making a raft", "power grid" and "thunder array" have never been learnt in the book and haven't been taught by anyone. In order to finish these tasks, you have to depend on yourselves to excavate your imagination potential and give full play to your creativity and manipulative ability. In the process of finishing these tasks, you may come to discover how your imagination is rich and how your manipulative capacity is strong. Quite a large number of university students have such feeling after they finish the program of "thunder array" that it is the key to gain success to break through the former thinking set, and have the courage to imagine and make an attempt.

\section{Feasibility Analysis of Introducing Outward Bound to Universities in Shandong Province}

\subsection{Activity Advantages of Outward Bound}

In outward bound, some programs can be carried out indoors and some can be carried out outdoors. Therefore, in accordance with specific weather conditions, teachers may have a flexible choice of appropriate activity programs. The same training target can have several programs for choice which can achieve the effect of being equally satisfactory in the result though different in approaches. Some activity apparatus may not necessarily purchase expensive equipment and can completely be used and adjusted according to local conditions.

\subsection{The Problem of Safety}

Whether in the traditional physical education or in the outward bound, physical activities are mostly done outdoors. Thus, the problem of safety, all without exception, has aroused enough attention. There are some programs in the outward bound which seem quite thrilling. Then, safety guarantee is the first priority in outward bound. Professional means and professional personnel are required to ensure absolute safety of each detail. As a matter of fact, in an outward bound in a physical education class, it is totally possible to successfully finish a program so long as teachers organize rationally, operate in accordance with stipulations, eliminate potential unsafe hazards in due course and take control over unsafe elements.

\section{3 "Teaching in Joy" in the Design of Outward Bound Programs}

All kinds of games and activities are organized in an outward bound to let students get a mastery of movement skills in joyful participation, perceive the principles implied, stimulate students' enthusiasm in "participation" and make the physical education class no longer dull.

\subsection{The Problem of Teacher Quality in Outward Bound}

The problem of teacher quality, without doubt, is quite important to the quality of physical education. A critical 
element in an outward bound is the capacity of organization, supervision, leading and inductive learning of training teachers. At present, almost all university physical education teachers have ever received systematic professional knowledge and learning as well as cultivation of skills and have abundant experiences in teaching. All these are necessary qualities for teachers engaged in an outward bound. Therefore, it is believed that after we introduce the outward bound into a physical education class, a large majority of physical education teachers are qualified for the job of teaching an outward bound so long as they receive relevant training on outward bound and their knowledge in pedagogy, management, organizational behavior and psychology is further consolidated. In addition, it is also feasible to provide training on university physical education teachers by means of organizing provincial learning classes and letting all physical education teachers to get the opportunity to receive corresponding learning and timely exchange. Besides, appointment taken with a certificate is necessary to guarantee the quality of the outward bound teaching.

\subsection{The Problem of Expense in Outward Bound}

Without doubt, the expense on constructing a qualified outward bound base is high, while a regular university or college may not have the strength in this regards. Therefore, we need to learn to make full use of surrounding resources and gain the maximum benefit with the minimum input. For the time being, the programs of outward bound in this country mainly contain the three kinds of field, overwater and outdoors. All these three kinds of programs have no high demand on the activity field, apparatus or facility and the cost is relatively low. Hence, the university, the park and the square can all be used as the training field and surrounding rivers and swimming pools can also be made full use of. As for a tiny minority of outward bound programs which require relatively expensive equipment, it is enough to resort to simulation or rent so as to cut down on cost. For example, the sand table required for outdoor orienteering may be replaced by a simple map designed by a student from the department of geography. In the meantime, it is also feasible to adopt university-university joint cooperation to construct an outward base, which not only economizes cost, but also yields twice the result with only half the effort. Operation of marketization can be employed in management of the outward bound base. This is not only helpful for maintenance of the base facility, but also adds to the financial strength of the university.

\subsection{To Combine Outward Bound with Other Physical Education Courses to Complement Each Other's Advantages}

Just as was discovered in our survey, the effect of outward bound on developing students' physical quality is not quite obvious. Instead, it is more obvious in stimulating students' interest in exercise, realize the two educational objectives of both psychological and social adaptation and develop students' physical quality so as to serve for the common objective in physical education.

\section{Conclusions and Suggestions}

1) With regards to the field apparatus and teacher quality in the current university physical education curriculum, implementation of outward bound in university physical education class is both necessary and feasible whether in terms of theory or in terms of practice.

2) Indeed, there is necessity to bring in outward bound into the university physical education class. Nevertheless, there is still a large distinction between outward bound and the traditional physical education curriculum. Therefore, it is necessary to try to integrate with the physical education class in terms of curriculum setting and evaluation standard, etc.

3) The essence of an outward bound class is "learning by doing". Therefore, we have to take full consideration of the subjectivity of students in the process of curriculum compilation. Likewise, we also have to give full play to the advantages of the university in itself in the process of opening such curriculum.

4) Introduction of Outward Bound Need to Proceed Step by Step and Adjust Measures to Local Conditions. Introduction of outward bound should take into consideration of certain principles, and, instead, prohibit rash advance. This is mainly to know about the major objective and connotation of the outward bound by learning relevant materials. Of course, it is also feasible to go to an outward bound club in the society for on-site learning and observation and to know about the program content, training process and organizational method of the outward bound. After a preliminary understanding of the outward bound, it is then necessary to make a pertinent analysis of the characteristics of university students and organically combine the training method of the outward bound club in the society together with university physical teaching. First of all, it is necessary to launch some simple campus programs with low danger and accumulate some experiences. On one hand, this enhances university teachers' comprehension in the outward bound. On the other hand, this also lays a foundation for scientific design of the content of an outward bound. Meanwhile, it is necessary to adjust measures in accordance 
with local conditions and set programs and a scene according to existing conditions. Then, we may further discover existing environmental resources both inside and outside the campus and make the outward bound better and faster integrated into the university gymnastics curriculum system.

5) Emphasizing the Safety Consciousness and Taking Safety Measures. In an outward bound, safety is regarded as the first important responsibility of training and every participant should keep high guard and ensure absolute safety of each detail with a professional means. All activities should go through careful design and experiment and the preparation job at an earlier stage should be done well. A pre-arranged plan should be made in accordance with changing circumstances and operation should be made according to the requirement so as to eliminate any potential unsafe hazard in the due course. A program is probable to successfully proceed so long as the participants are organized in a rational way and operate in according to the requirement, get rid of any unsafe condition in the due course, put an end to any unsafe behavior and take control over any unsafe element.

\section{References}

Chen, J. X. (1997). Discussion on Outward Bound and Its Enlightenment on Basic Education in China. Education Research, (5).

Liu, L. (2010). Meaning and Approach of Outward Bound Programs in University Physical Education Class. Guide of Sci-tech Magazine, (5).

Qian, Y. J. (2006). Outward Bound. Beijing: Enterprise Management Publishing House.

Wang, Z. B. (2009). Feasibility Discussion on Physical Outward Bound in Universities and Colleges. China Education Innovation Herald, (4).

Zhang, Y. Q. (2003). Thought on Introducing Outward Bound to University Physical Education Class. Liaoning Sport Science and Technology, (8).

\section{Copyrights}

Copyright for this article is retained by the author(s), with first publication rights granted to the journal.

This is an open-access article distributed under the terms and conditions of the Creative Commons Attribution license (http://creativecommons.org/licenses/by/3.0/). 